\title{
Sex-specific genetic effects influence variation in body composition
}

\author{
M. C. Zillikens • M. Yazdanpanah • L. M. Pardo • \\ F. Rivadeneira • Y. S. Aulchenko • B. A. Oostra • \\ A. G. Uitterlinden • H. A. P. Pols • C. M. van Duijn
}

Received: 25 April 2008 / Accepted: 2 September 2008 / Published online: 7 October 2008

(C) The Author(s) 2008. This article is published with open access at Springerlink.com

\begin{abstract}
Aims/hypothesis Despite well-known sex differences in body composition it is not known whether sex-specific genetic or environmental effects contribute to these differences.

Methods We assessed body composition in 2,506 individuals, from a young Dutch genetic isolate participating in the Erasmus Rucphen Family study, by dual-energy X-ray absorptiometry and anthropometry. We used variance decomposition procedures to partition variation of body composition into genetic and environmental components common to both sexes and to men and women separately and calculated the correlation between genetic components in men and women.

Results After accounting for age, sex and inbreeding, heritability ranged from 0.39 for fat mass index to 0.84 for height. We found sex-specific genetic effects for fat percentage (fat $\%$ ), lean mass, lean mass index (LMI) and fat distribution, but not for BMI and height. Genetic correlations
\end{abstract}

Electronic supplementary material The online version of this article (doi:10.1007/s00125-008-1163-0) contains supplementary material, which is available to authorised users.

M. C. Zillikens $(\bowtie) \cdot$ M. Yazdanpanah $\cdot$ F. Rivadeneira $\cdot$

A. G. Uitterlinden • H. A. P. Pols

Department of Internal Medicine, Erasmus Medical Centre,

P.O. Box 2040, 3000 CA Rotterdam, the Netherlands

e-mail: m.c.zillikens@erasmusmc.nl

L. M. Pardo $\cdot$ F. Rivadeneira $\cdot$ Y. S. Aulchenko $\cdot$ B. A. Oostra

A. G. Uitterlinden $\cdot$ H. A. P. Pols $\cdot$ C. M. van Duijn

Genetic Epidemiology Unit, Departments of Epidemiology \&

Biostatistics and Clinical Genetics, Erasmus Medical Centre,

Rotterdam, the Netherlands

L. M. Pardo

Medical Genomics Section, Department of Clinical Genetics,

VU University Medical Center,

Amsterdam, the Netherlands between sexes were significantly different from 1 for fat $\%$, lean mass, LMI, android fat, android:gynoid fat ratio and WHR, indicating that there are sex-specific genes contributing to variation of these traits. Genetic variance was significantly higher in women for the waist, hip and thigh circumference and WHR, implying that genes account for more variance of fat distribution in women than in men. Environmental variance was significantly higher in men for the android: gynoid fat ratio.

Conclusions/interpretation Sex-specific genetic effects underlie sexual dimorphism in several body composition traits. The findings are relevant for studies on the relationship of body composition with common diseases like cardiovascular disease and type 2 diabetes and for genetic association studies.

Keywords Anthropometry - Body composition - DXA . Fat distribution · Heritability - Sex-specific genetic effects . Sexual dimorphism

$\begin{array}{ll}\text { Abbreviations } \\ \rho \mathrm{G} & \text { genetic correlation } \\ \sigma & \text { standard deviation } \\ \sigma \mathrm{E} & \text { environmental standard deviation } \\ \sigma \mathrm{E}_{\mathrm{F}} & \text { environmental standard deviation female } \\ \sigma \mathrm{E}_{\mathrm{M}} & \text { environmental standard deviation male } \\ \sigma \mathrm{G} & \text { genetic standard deviation } \\ \sigma \mathrm{G}_{\mathrm{F}} & \text { genetic standard deviation female } \\ \sigma \mathrm{G}_{\mathrm{M}} & \text { genetic standard deviation male } \\ \sigma^{2} \mathrm{E} & \text { environmental variance } \\ \sigma^{2} \mathrm{E}_{\mathrm{F}} & \text { environmental variance female } \\ \sigma^{2} \mathrm{E}_{\mathrm{M}} & \text { environmental variance male } \\ \sigma^{2} \mathrm{G} & \text { genetic variance } \\ \sigma^{2} \mathrm{G}_{\mathrm{F}} & \text { genetic variance female } \\ \sigma^{2} \mathrm{G}_{\mathrm{M}} & \text { genetic variance male }\end{array}$




$\begin{array}{ll}\text { DXA } & \text { dual-energy x-ray absorptiometry } \\ \text { ERF study } & \text { Erasmus Rucphen Family study } \\ \mathrm{E} \times \mathrm{S} & \text { environment by sex interaction } \\ \text { fat } \% & \text { fat percentage } \\ \mathrm{FMI} & \text { fat mass index } \\ \mathrm{G} \times \mathrm{S} & \text { genotype by sex interaction } \\ \mathrm{h}^{2} & \text { heritability } \\ \text { LMI } & \text { lean mass index } \\ \text { WHR } & \text { waist:hip ratio } \\ \text { WTR } & \text { waist:thigh ratio }\end{array}$

\section{Introduction}

Obesity has become a global epidemic and represents an important risk factor for type 2 diabetes mellitus, hypertension, cardiovascular disease, stroke, some types of cancer and disability. Although the growing prevalence of obesity is most probably caused by increasing energy intake and decreasing energy expenditure by physical activity, individual susceptibility varies widely and is strongly influenced by genetic factors. Twin, adoption and family studies have shown that between $40 \%$ and $80 \%$ of inter-individual variation of BMI is heritable [1-3]. There are also significant genetic influences on obesity-related traits like total body fat mass, lean mass and measures of fat distribution [4-8], but the heritability of these variables is less clear than that of BMI.

Although the importance of sex as a key determinant in health and illness has been recognised for a long time [9], systematic studies of sex differences in medicine are still lacking. There is a well-known sexual dimorphism in human body composition, with adult men having greater body height, total lean mass and bone mineral mass, and a lower fat mass than women [10]. Moreover, there are differences in fat distribution, with men showing more upper body or so-called 'android' distribution of adipose tissue and women a more peripheral or 'gynoid' distribution, with bigger hips and thighs.

Given the large genetic effects on body composition, it is possible that different (although partly overlapping) genes contribute to variation in body composition in men and women and/or that the genetic determinants of body composition may be modulated by sex-specific hormonal, environmental and nutritional factors. Despite its genetic determination, sex can also be considered an environmental factor that can modify both the penetrance and expressivity of a wide variety of traits $[11,12]$. Evidence for sex-specific genetic effects (or a genotype by sex interaction $[\mathrm{G} \times \mathrm{S}]$ ) on body composition, however, is scarce since few studies have systematically investigated potential sex differences in the genetic architecture of body composition. Studies on sex differences in heritability of BMI have shown inconsistent results. Some studies found evidence for a higher heritability of BMI in women than in men [2, 3, 12-14] or the other way around [15-17] or no difference [18, 19]. In the Diabetes Heart Study [7], heritability estimates were larger in women for BMI and lean mass but not for fat percentage (fat $\%$ ) assessed by dual-energy x-ray absorptiometry (DXA). However, these differences were considered not significant considering the large SEs. Sex-specific differences in heritability can be caused by differences in additive genetic variance, non-genetic (environmental) variance or total phenotypic variance. Using variance decomposition procedures, also known as variance components analysis, variation in traits can be partitioned into genetic and environmental components and genetic correlations can be calculated between men and women. Using this procedure, Comuzzie et al. [20] found evidence for $G \times S$ interaction for several anthropometric variables in Mexican-Americans, but no data were available in this study on fat and lean mass.

The aim of the present study was to determine heritability of a large set of body composition variables determined by DXA and anthropometry in a large extended pedigree from a genetically isolated population in the Netherlands and to explore potential sex-specific differences in the relative influence of genetic and environmental factors on body composition. Specifically, we considered the following questions: (1) are there different genes that contribute to the variation of body composition in men and women (i.e. are there qualitative sex differences); and (2) is the magnitude of the genetic and/or environmental variation larger in one sex than in the other (i.e. are there quantitative sex differences in genetic and/or environmental variances)?

\section{Methods}

Study population This study was carried out within the Erasmus Rucphen Family (ERF) study, a family-based cohort study that is embedded in the Genetic Research in Isolated Populations programme in the South West of the Netherlands. The aim of this programme is to identify genetic risk factors in the development of complex disorders [21-23]. Genealogical records demonstrated that almost all of the inhabitants of this isolated population could be traced back to about 150 individuals who founded this community about the year 1750 . The population is characterised by minimal immigration up until the last few decades. About 20,000 inhabitants are now scattered over eight adjacent villages. Genealogical information on this population was reconstructed using church and municipality records and is currently available in the form of a large database including over 63,000 individual records.

For the ERF study, 22 families that had at least five children baptised in the community church between 1850 
and 1900 were identified with the help of genealogical records. All living descendants of these couples and their spouses were invited to take part in the study. Data collection started in June 2002 and was finished in February 2005. In this study, we focused on the 2,506 participants for whom complete phenotypic and genealogical information was available. PEDSTATS [24] was used to produce summary statistics of the pedigree and correlations of the variables by pair type.

The Medical Ethics Committee of the Erasmus Medical Centre Rotterdam approved the study. Written informed consent was obtained from all participants.

Data collection At the research centre, located within the community, extensive clinical examinations were performed, including the collection of fasting blood samples, anthropometric measurements and personal interviews. A research physician obtained information on medical history, medication use, smoking and alcohol use in a personal interview.

Anthropometric measurements Anthropometric measurements Height and weight were measured with the participant dressed in light underclothing. BMI was calculated from these data as weight $(\mathrm{kg}) /$ height $^{2}\left(\mathrm{~m}^{2}\right)$. Circumferences of the waist, hip and thigh were measured on uncovered skin using a tape measure with the participant in the upright position. Waist circumference was measured halfway between the rib cage and the pelvic bone. Hip circumference was measured at the maximal circumference of the hips. Thigh circumference was measured mid-way between the upper border of the patella and the inguinal fold on the right leg. The WHR and waist:thigh ratio (WTR) were calculated from these measurements. Figure 1a shows the sites of circumference measurements.

DXA measurements DXA scans were performed using a Prodigy total-body fan-beam densitometer and analysed with enCORE 2005 software v.9.3 (DPX; Lunar, Madison, a

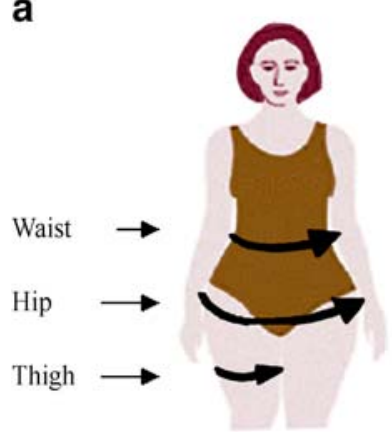

Circumferences b

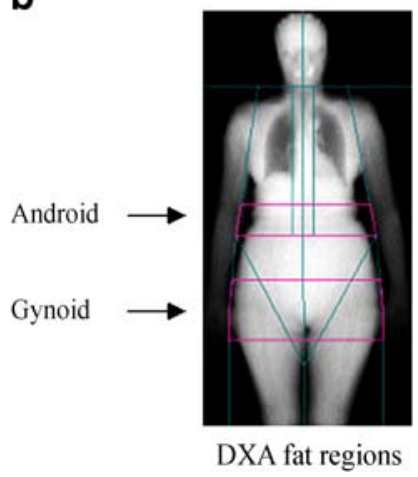

Fig. 1 a Sites of the circumference measurements. b Regions of 'android' and 'gynoid' fat assessed by DXA
WI, USA). Total body scans were auto-analysed with this software, in which an algorithm that divides body measurements into areas corresponding to head, trunk, arms and legs is implemented. Total body fat mass (g), lean mass (g) and regional fat mass were obtained from total body scans. The trunk region was limited by an upper horizontal border below the chin (neck cut), vertical borders lateral to the ribs, and a lower border by the iliac crest. The arm region was limited by cuts that cross the arm sockets, as close to the body as possible and separate the arms and hands from the body. The leg region is limited above by the oblique lines passing through the hip joint, and cuts that separate the hands and forearms from the legs and a centre leg cut which separates the right and left leg. Two additional regions were defined using the software provided by the manufacturer; the so-called 'android' and 'gynoid' region. The 'android' region has a lower boundary at the pelvis cut and the upper boundary above the pelvis cut by $20 \%$ of the distance between the pelvis and neck cuts. The lateral boundaries are the arm cuts. The 'gynoid region' has an upper boundary between the upper part of the greater trochanters and a lower boundary defined at a distance equal to twice the height of the 'android' region. The lateral boundaries are the outer leg cuts. The android and gynoid fat mass and android:gynoid fat ratio were calculated from these measurements. A schematic representation of the android and gynoid region is shown in Fig. 1b. All analyses were verified by a trained technician who performed adjustments when necessary. Daily quality-assurance tests were performed with a calibration block supplied by the manufacturer. Repeated measurements on the calibration block had $\mathrm{CV}$ values $<1 \%$.

Definitions Body weight $=$ total fat mass + total lean mass + bone mineral content. BMI=body weight $(\mathrm{kg}) /$ height $^{2}\left(\mathrm{~m}^{2}\right)$. Fat mass index $(\mathrm{FMI})=$ total fat mass $(\mathrm{kg}) /$ height $^{2}\left(\mathrm{~m}^{2}\right)$. Lean mass index $(\mathrm{LMI})=$ total lean mass $(\mathrm{kg}) /$ height $^{2}\left(\mathrm{~m}^{2}\right)$. Total body fat $\%=($ total fat mass/body weight $) \times 100$.

Statistical analysis Baseline characteristics for men and women were compared using the Mann-Whitney $U$ test in SPSS for Windows, version 11.0. Inbreeding coefficients were computed with PEDIG software [25], using all the available genealogical information. Spearman correlations between inbreeding values and the body composition phenotypes were calculated using SPSS. General linear models were used to test phenotypic association between various body composition variables. In order to satisfy distributional assumptions, the phenotype distributions were normalised by natural log or square root transformation to ensure normally distributed residuals. A full pedigree variance components approach based on maximum-likelihood methods as implemented in the SOLAR 2.1.2 (Sequential Oligogenic Linkage Analysis Routines) software package was used to estimate the heritability of 
body composition variables [26]. Univariate quantitative genetic analysis was performed to partition the phenotypic variance of body composition variables into additive genetic and environmental variance components using maximumlikelihood variance decomposition methods [27, 28].

The phenotypic variance of the body composition variables, which reflects the inter-individual variation, was partitioned into its additive genetic $\left(\sigma^{2} \mathrm{G}\right)$ and residual environmental $\left(\sigma^{2} \mathrm{E}\right)$ variance components [29]. Heritability was estimated as the ratio of the additive genetic variance to the sum of the additive genetic and environmental variance, that is including sources of residual variance as measurement error: $\mathrm{h}^{2}=$ (additive) $\sigma^{2} \mathrm{G} /\left(\sigma^{2} \mathrm{G}+\sigma^{2} \mathrm{E}\right)$. Dominance variance, which, in conjunction with additive and environmental variance, comprises broad sense heritability, was not estimated. Dominance effects are more easily modelled in twin than in family studies but they are difficult to model in extended pedigrees. Similarly to the assumptions made in current genome wide association studies, we assumed additive effects.

To evaluate sex-specific effects on the variation of body composition variables we used a standard sex-limitation modelling approach that allows testing for specific patterns of interaction, such as $\mathrm{G} \times \mathrm{S}[20,30-32]$. The test for $\mathrm{G} \times \mathrm{S}$ interactions is based on hypotheses concerning the nature of the variance-covariance relationship of a trait between male-female relative pairs The expected genetic covariance (or shared heritability) between a male and female relative pair is defined as covariance $\left(\mathrm{G}_{\mathrm{M}}, \mathrm{G}_{\mathrm{F}}\right)=2 \varphi \rho \mathrm{G}_{(\mathrm{M}, \mathrm{F})} \sigma \mathrm{G}_{\mathrm{M}}$ $\sigma \mathrm{G}_{\mathrm{F}}$ where $\varphi$ is the coefficient of kinship between the two individuals, $\rho \mathrm{G}_{(\mathrm{M}, \mathrm{F})}$ the genetic correlation between the expressions of the trait in the two sexes, and $\sigma G_{\mathrm{M}}$ and $\sigma G_{\mathrm{F}}$ the genetic SDs for men and women.

In the absence of a $\mathrm{G} \times \mathrm{S}$ interaction (i.e. the null hypothesis), the genetic correlation between male and female relative pairs should be $1\left(\rho \mathrm{G}_{(\mathrm{M}, \mathrm{F})}=1.0\right)$ and male and female genetic SDs will be equivalent $\left(\sigma \mathrm{G}_{\mathrm{M}}=\sigma \mathrm{G}_{\mathrm{F}}\right)$. Conversely, if there is $\mathrm{G} \times \mathrm{S}$ interaction, the genetic correlation between the sexes, $\rho \mathrm{G}_{(\mathrm{M}, \mathrm{F})}$ will be significantly $<1.0$ (implying qualitative sex differences) and/or the genetic SDs will be significantly different between the sexes $\left(\sigma \mathrm{G}_{\mathrm{M}} \neq \sigma \mathrm{G}_{\mathrm{F}}\right)$, implying quantitative sex differences in the genetic variance. Additionally, environment by sex interactions $(\mathrm{E} \times \mathrm{S})$, or quantitative differences in the environmental variance, would be indicated by the environmental SDs not being equal between the sexes $\left(\sigma \mathrm{E}_{\mathrm{M}} \neq \sigma \mathrm{E}_{\mathrm{F}}\right)$.

To evaluate $\mathrm{G} \times \mathrm{S}$ interactions influencing body composition traits, a full model was fitted, in which $\rho \mathrm{G}, \sigma \mathrm{G}_{\mathrm{M}}$, $\sigma \mathrm{G}_{\mathrm{F}}, \sigma \mathrm{E}_{\mathrm{M}}$ and $\sigma \mathrm{E}_{\mathrm{F}}$ variables were freely estimated using maximum-likelihood methods. In addition, we fitted three nested models, in which one of these variables was constrained, as follows: model 1 , in which the genetic correlation between men and women was constrained to 1 ( $\rho \mathrm{G}=1$ ); model 2, in which genetic SDs were constrained to be equal $\left(\sigma \mathrm{G}_{\mathrm{M}}=\sigma \mathrm{G}_{\mathrm{F}}\right)$; and model 3, in which environmental SDs were constrained to be equal $\left(\sigma \mathrm{E}_{\mathrm{M}}=\sigma \mathrm{E}_{\mathrm{F}}\right)$. Likelihood ratio tests (LRTs) were used to test whether the nested models fit the data significantly worse than the full model. The LRT statistic follows an asymptotic $\chi^{2}$ distribution with $1 d f$ when comparing the full model with the nested models, in which the SDs were constrained to be equal (full model against model 2; and full model against model 3). However, in the case of the model that restricted the genetic correlation to 1, this assumption does not hold, since the genetic correlation was constrained to the upper boundary of the variable space $(\rho \mathrm{G}=1)$. As a result of this constraint, the test statistic is not distributed as an asymptotic $\chi_{1}^{2}$ distribution, but rather as a $1 / 2: 1 / 2$ mixture of a $\chi_{1}^{2}$ distribution and a point mass at zero [31-33].

Three basic inferences concerning the nature of sexbased interactions can be made: (1) rejection of the model constraining the genetic correlation between the groups to 1 $\left(\rho \mathrm{G}_{(\mathrm{M}, \mathrm{F})}=1.0\right)$ implies that different genes or a different subset of genes contribute to the variance in body composition variables in men and women; (2) rejection of the model constraining the genetic SDs of the groups to be equal $\left(\sigma \mathrm{G}_{\mathrm{M}}=\sigma \mathrm{G}_{\mathrm{F}}\right)$ implies that the magnitude of the genetic effect is different between the two sexes; and (3) rejection of the model constraining the environmental SDs of the groups to be equal $\left(\sigma \mathrm{E}_{\mathrm{M}}=\sigma \mathrm{E}_{\mathrm{F}}\right)$ implies an interaction between the residual environment and the sex.

All analyses were adjusted for age and inbreeding quartiles (given that the distribution of inbreeding coefficients was not normally distributed) and for sex when heritability was estimated for both men and women.

\section{Results}

Table 1 shows the number of pairs of relatives present in the large pedigree. The average number of generations in the pedigree used for analysis was 5.6 (range 4-7) and the average family size was 113.9 (range 34-268). The average number of women per family was 63.9 (range 18-145) and of men 50.1 (range 13-123).

Table 2 shows the general characteristics of the study population. As expected, men had significantly increased body height, weight, lean mass and LMI, while body fat (total fat, FMI and fat $\%$ ) was lower than in women. Android fat was significantly higher in men while gynoid fat was higher in women. Thus, the android:gynoid fat ratio was higher in men as well as the WHR.

The median inbreeding coefficient (interquartile range) was $0.002(0.008)$. Inbreeding was significantly correlated with some traits, namely: height (Spearman $r=-0.163, p<0.01$ ), weight $(r=-0.082, p<0.01)$, fat mass $(r=-0.043, p<0.05)$, lean mass $(r=-0.076, p<0.01)$, gynoid fat mass $(r=-0.042$, 
Table 1 Number of relative pairs within the pedigree of the ERF study population

\begin{tabular}{|c|c|c|c|c|c|}
\hline \multirow[t]{2}{*}{ Characteristic } & \multicolumn{5}{|l|}{ Pairs } \\
\hline & Total & Phenotyped subset & Female-female & Male-male & Opposite sex \\
\hline Pedigree members & 4,283 & 2,506 & & & \\
\hline Number of families & 22 & 22 & & & \\
\hline Founders & 1,389 & 479 & & & \\
\hline Non-founders & 2,894 & 2,027 & & & \\
\hline \multicolumn{6}{|l|}{ Relative pairs } \\
\hline Sib-pairs & 3,436 & 1,454 & 459 & 285 & 710 \\
\hline Half-sibs & 101 & 53 & 19 & 8 & 26 \\
\hline Cousins & 13,614 & 5,906 & 1,782 & 1,201 & 2,923 \\
\hline Parent-child & 5,788 & 1,560 & 508 & 303 & 749 \\
\hline Grandparent-grandchild & 5,556 & 156 & 61 & 23 & 72 \\
\hline Avuncular & 10,741 & 2,851 & 883 & 611 & 1,357 \\
\hline
\end{tabular}

Number of relative pairs in columns 3, 4 and 5 denotes the number for which phenotypic information is available for both members of the pairs

$p<0.01)$ and thigh circumference $(r=-0.037, p<0.05)$, but not with BMI, FMI, fat $\%$, LMI, android fat mass, android: gynoid fat ratio, waist and hip circumference, WHR and WTR.

Table 3 shows the genetic and residual environmental variance and heritability estimates for men and women combined after accounting for age, sex and inbreeding. Heritability estimates ranged from 0.39 for FMI to 0.84 for body height. The heritability estimate for body weight $(0.52)$ was higher than that for BMI $(0.44)$ possibly because weight is related strongly to the highly heritable trait body height while BMI is corrected for height. A similar trend was seen for the heritability estimate of fat mass $(0.46)$ vs FMI (0.39) and lean mass (0.57) vs LMI (0.45). Heritability estimates of circumference measurements were between 0.40 (for waist) and 0.48 (for thigh). The heritability estimates of the circumference ratios WHR and WTR were 0.40 and similar to the fat distribution variable estimated by DXA in the form of the android:gynoid fat ratio (0.43).

Correlations for each trait by pair type can be found in the Electronic supplementary material (ESM) Table 1, or are available upon request.

Tables 4 and 5 show the results of the sex-specific genetic analyses on the variation of the body composition traits, including the heritability estimates for women and men separately with the sex-specific estimates of genetic and environmental variances $\left(\sigma^{2}\right)$ and the correlation between genetic components of body composition variables in men and women $(\rho \mathrm{G})$. We found evidence for sexspecific genetic effects for all traits except for height, BMI, gynoid fat mass and the WTR ratio, while for body weight and fat mass and FMI this evidence was borderline significant $(p=0.06)$ (Table 5). The genetic correlations between men and women were significantly different from 1 for fat $\%$, lean mass, LMI, android fat, android:gynoid fat ratio and WHR (Table 5). This indicates that different genes or a different subset of genes contribute to the variance of these body composition variables in men and women. The genetic variance was significantly higher in women than in men for the waist, hip and thigh circumference and for WHR (Tables 4 and 5). For the WHR, the genetic correlation was, in addition, significantly different from 1 . This indicates that for the circumference measurements we found no evidence that different genes contribute to variation in these body composition variables but these same genes account for a larger magnitude of the genetic effect in women than in men. Evidence for an $\mathrm{E} \times \mathrm{S}$ interaction was found only for the android:gynoid fat ratio, with men showing significantly greater environmental variance for this trait than women $(p<0.01)$. For lean mass, total fat mass and

Table 2 General characteristics of the ERF study population

\begin{tabular}{llll}
\hline Characteristic & Women & Men & $p$ value \\
\hline$n$ & 1,405 & 1,101 & \\
Age (years) & $47.5 \pm 14.5$ & $48.2 \pm 14.2$ & $<0.01$ \\
Height $(\mathrm{m})$ & $1.62 \pm 0.06$ & $1.75 \pm 0.07$ & $<0.01$ \\
Weight $(\mathrm{kg})$ & $69.3 \pm 13.2$ & $83.2 \pm 13.9$ & $<0.01$ \\
BMI $\left(\mathrm{kg} / \mathrm{m}^{2}\right)$ & $26.4 \pm 4.9$ & $27.3 \pm 4.2$ & $<0.01$ \\
Total fat mass $(\mathrm{kg})$ & $26.5 \pm 9.8$ & $22.3 \pm 8.9$ & $<0.01$ \\
FMI $\left(\mathrm{kg} / \mathrm{m}^{2}\right)$ & $10.1 \pm 3.7$ & $7.3 \pm 2.9$ & $<0.01$ \\
Fat $\%$ & $37.4 \pm 7.5$ & $26.0 \pm 7.0$ & $<0.01$ \\
Total lean mass $(\mathrm{kg})$ & $39.9 \pm 4.9$ & $57.9 \pm 7.0$ & $<0.01$ \\
LMI $\left(\mathrm{kg} / \mathrm{m}^{2}\right)$ & $15.2 \pm 1.7$ & $19.0 \pm 1.9$ & $<0.01$ \\
Android fat mass $(\mathrm{kg})$ & $2.34 \pm 1.2$ & $2.57 \pm 1.2$ & $<0.01$ \\
Gynoid fat mass $(\mathrm{kg})$ & $5.09 \pm 1.54$ & $3.61 \pm 1.3$ & $<0.01$ \\
Android:gynoid fat $\mathrm{ratio}$ & $0.45 \pm 0.15$ & $0.71 \pm 0.20$ & $<0.01$ \\
Waist circumference $(\mathrm{cm})$ & $81.5 \pm 12.2$ & $93.7 \pm 11.7$ & $<0.01$ \\
Hip circumference $(\mathrm{cm})$ & $101.3 \pm 9.3$ & $99.3 \pm 7.3$ & $<0.01$ \\
Thigh circumference $(\mathrm{cm})$ & $50.3 \pm 5.4$ & $50.9 \pm 4.9$ & $<0.01$ \\
WHR & $0.80 \pm 0.08$ & $0.94 \pm 0.08$ & $<0.01$ \\
WTR & $1.63 \pm 0.20$ & $1.85 \pm 0.20$ & $<0.01$ \\
\hline
\end{tabular}

Values are presented as percentage or mean $\pm \mathrm{SD}$ 
Table 3 Heritability estimates and variance components of the body composition variables in 2,506 male and female ERF participants

\begin{tabular}{lrrr}
\hline & \multicolumn{1}{c}{$\sigma^{2} \mathrm{G}$} & \multicolumn{1}{c}{$\sigma^{2} \mathrm{E}$} & $\mathrm{h}^{2}$ \\
\hline Height $(\mathrm{m})$ & $28.44(1.78)$ & $5.56(0.98)$ & 0.84 \\
Weight $(\mathrm{kg})$ & $1.56(0.15)$ & $1.44(0.12)$ & 0.52 \\
BMI $\left(\mathrm{kg} / \mathrm{m}^{2}\right)$ & $8.59(1.01)$ & $11.11(0.95)$ & 0.44 \\
Total fat mass $(\mathrm{kg})$ & $0.40(0.04)$ & $0.47(0.04)$ & 0.46 \\
FMI $\left(\mathrm{kg} / \mathrm{m}^{2}\right)$ & $5.96(0.73)$ & $9.43(0.70)$ & 0.39 \\
Total fat mass $(\%)$ & $21.33(2.41)$ & $29.13(2.12)$ & 0.42 \\
Lean mass $(\mathrm{kg})$ & $9.35(0.86)$ & $7.01(0.63)$ & 0.57 \\
LMI $\left(\mathrm{kg} / \mathrm{m}^{2}\right)$ & $1.82(0.21)$ & $2.25(0.19)$ & 0.45 \\
Android fat mass $(\mathrm{kg})$ & $5.65(0.63)$ & $7.44(0.55)$ & 0.43 \\
Gynoid fat mass $(\mathrm{kg})$ & $5.29(0.54)$ & $5.58(0.44)$ & 0.49 \\
Android:gynoid fat ratio & $0.95(0.11)$ & $1.24(0.09)$ & 0.43 \\
Waist circumference $(\mathrm{cm})$ & $0.64(0.08)$ & $0.95(0.07)$ & 0.40 \\
Hip circumference $(\mathrm{cm})$ & $0.30(0.03)$ & $0.36(0.03)$ & 0.46 \\
Thigh circumference $(\mathrm{cm})$ & $0.46(0.05)$ & $0.51(0.04)$ & 0.48 \\
WHR & $1.20(0.14)$ & $1.77(0.12)$ & 0.40 \\
WTR & $0.32(0.04)$ & $0.46(0.03)$ & 0.40 \\
\hline
\end{tabular}

Estimates were adjusted for sex, age and inbreeding. Values are presented as variance (SE)

gynoid fat mass, differences were of borderline significance $(p=0.05-0.07)$.

\section{Discussion}

In this study we found evidence for a difference in genetic background between men and women for most of the body composition variables studied, namely for fat $\%$, lean mass,
LMI, and for measures of fat distribution by circumferences and by DXA. Specifically, the magnitude of the genetic correlations was significantly different from 1 for fat $\%$, lean mass, LMI, android fat, android:gynoid fat ratio and WHR, indicating that different genes or different, although partly overlapping, subsets of genes contribute to variation of these traits in men and women. Furthermore, genetic variance was almost twice as large in women as in men for all circumferences and for WHR, suggesting that genetic determinants of fat distribution account for more variance in women. For height, BMI, gynoid fat mass and the WTR differences between the sexes were not significant while for weight, fat mass and FMI they were borderline significant. Evidence for sex-specific environment effects was only found for the android:gynoid fat ratio, with men showing significantly greater environmental variance then women, with borderline significant differences for lean mass, total fat mass and gynoid fat mass.

The finding of small but significantly negative correlations between inbreeding and some of the traits, especially height, could point towards recessive alleles.

Our results of no sex-specific genetic effects for BMI are in agreement with some family studies [18, 19], but they are in contrast with twin studies that found higher $[2,3,13$, 14], or lower [15-17] heritability estimates in women than in men. Schousboe et al. [6] found slight differences between women and men in the extent of additive genetic and common environmental influences on BMI, anthropometric measures of fat distribution and fat $\%$ and LMI estimated by bioelectrical impedance in twins, but CIs were broad and overlapped for most estimates. In the Diabetes

Table 4 Sex-specific variance components for the body composition variables in 2,506 ERF participants

\begin{tabular}{|c|c|c|c|c|c|c|c|}
\hline & \multicolumn{3}{|l|}{ Women } & \multicolumn{3}{|l|}{ Men } & \multirow[t]{2}{*}{$\rho \mathrm{G}$} \\
\hline & $\sigma^{2} \mathrm{G}$ & $\sigma^{2} \mathrm{E}$ & $h^{2}$ & $\sigma^{2} \mathrm{G}$ & $\sigma^{2} \mathrm{E}$ & $h^{2}$ & \\
\hline Height (m) & $1.08(0.09)$ & $0.18(0.06)$ & 0.86 & $1.29(0.12)$ & $0.21(0.08)$ & 0.86 & $0.96(0.05)$ \\
\hline Weight (kg) & $1.92(0.24)$ & $1.35(0.19)$ & 0.59 & $1.31(0.23)$ & $1.31(0.20)$ & 0.50 & $0.89(0.10)$ \\
\hline BMI $\left(\mathrm{kg} / \mathrm{m}^{2}\right)$ & $10.44(1.58)$ & $11.38(1.42)$ & 0.48 & $7.43(1.46)$ & $9.38(1.35)$ & 0.44 & $0.86(0.12)$ \\
\hline Total fat mass $(\mathrm{kg})$ & $0.48(0.06)$ & $0.36(0.05)$ & 0.57 & $0.38(0.08)$ & $0.51(0.07)$ & 0.43 & $0.82(0.11)$ \\
\hline FMI $\left(\mathrm{kg} / \mathrm{m}^{2}\right)$ & $15.81(2.26)$ & $14.86(1.93)$ & 0.52 & $11.40(2.32)$ & $16.46(2.15)$ & 0.41 & $0.81(0.12)$ \\
\hline Total fat mass $(\%)$ & $28.33(4.02)$ & $24.42(3.36)$ & 0.54 & $19.79(3.90)$ & $27.65(3.61)$ & 0.42 & $0.74(0.12)$ \\
\hline Lean mass $(\mathrm{kg})$ & $0.09(0.01)$ & $0.05(0.01)$ & 0.64 & $0.12(0.02)$ & $0.08(0.01)$ & 0.59 & $0.84(0.09)$ \\
\hline LMI $\left(\mathrm{kg} / \mathrm{m}^{2}\right)$ & $1.79(0.27)$ & $1.82(0.23)$ & 0.50 & $2.47(0.43)$ & $2.17(0.37)$ & 0.53 & $0.74(0.12)$ \\
\hline Android fat mass $(\mathrm{kg})$ & $0.07(0.01)$ & $0.06(0.01)$ & 0.54 & $0.06(0.01)$ & $0.07(0.01)$ & 0.43 & $0.75(0.12)$ \\
\hline Gynoid fat mass (kg) & $0.06(0.01)$ & $0.04(0.01)$ & 0.59 & $0.05(0.01)$ & $0.06(0.01)$ & 0.44 & $0.87(0.11)$ \\
\hline Android:gynoid fat ratio & $1.07(0.14)$ & $0.72(0.11)$ & 0.60 & $1.34(0.23)$ & $1.36(0.20)$ & 0.50 & $0.57(0.11)$ \\
\hline Waist circumference $(\mathrm{cm})$ & $0.90(0.13)$ & $0.89(0.11)$ & 0.50 & $0.50(0.11)$ & $0.83(0.11)$ & 0.38 & $0.77(0.14)$ \\
\hline Hip circumference $(\mathrm{cm})$ & $0.42(0.06)$ & $0.35(0.05)$ & 0.55 & $0.22(0.04)$ & $0.29(0.04)$ & 0.43 & $0.83(0.12)$ \\
\hline Thigh circumference $(\mathrm{cm})$ & $0.62(0.08)$ & $0.45(0.06)$ & 0.58 & $0.32(0.07)$ & $0.53(0.06)$ & 0.38 & $0.95(0.12)$ \\
\hline WHR & $1.73(0.26)$ & $1.81(0.22)$ & 0.49 & $0.93(0.21)$ & $1.30(0.19)$ & 0.42 & $0.73(0.13)$ \\
\hline WTR & $2.63(0.50)$ & $5.19(0.48)$ & 0.34 & $2.02(0.60)$ & $4.98(0.59)$ & 0.29 & $0.77(0.17)$ \\
\hline
\end{tabular}

Estimates were adjusted for age and inbreeding. Values are presented as variance (SE) 
Table 5 Model estimates from sex-specific variance partitioning of body composition variables in 2,506 ERF participants

\begin{tabular}{|c|c|c|c|c|c|c|c|c|c|c|}
\hline \multirow[t]{2}{*}{ Characteristic } & \multirow{2}{*}{$\begin{array}{l}\text { Log- } \\
\text { likelihood } \\
\text { (full model) }\end{array}$} & \multicolumn{3}{|l|}{$\rho \mathrm{G}=1$} & \multicolumn{3}{|l|}{$\sigma^{2} \mathrm{G}_{\mathrm{F}}=\sigma^{2} \mathrm{G}_{\mathrm{M}}$} & \multicolumn{3}{|l|}{$\sigma^{2} \mathrm{E}_{\mathrm{F}}=\sigma^{2} \mathrm{E}_{\mathrm{M}}$} \\
\hline & & $\begin{array}{l}\text { Log-likelihood } \\
\text { (nested model) }\end{array}$ & $\chi^{2}$ & $\begin{array}{l}p \\
\text { value }^{\mathrm{a}}\end{array}$ & $\begin{array}{l}\text { Log-likelihood } \\
\text { (nested model) }\end{array}$ & $\chi^{2}$ & $\begin{array}{l}p \\
\text { value }\end{array}$ & $\begin{array}{l}\text { Log-likelihood } \\
\text { (nested model) }\end{array}$ & $\chi^{2}$ & $\begin{array}{l}p \\
\text { value }\end{array}$ \\
\hline Height (m) & $-6,315.24$ & $-6,315.46$ & 0.44 & 0.25 & $-6,316.44$ & 2.41 & 0.13 & $-6,315.29$ & 0.11 & 0.74 \\
\hline Weight (kg) & $-3,399.15$ & $-3,399.72$ & 1.15 & 0.14 & $-3,400.94$ & 3.59 & 0.06 & $-3,399.15$ & 0.01 & 0.90 \\
\hline BMI $\left(\mathrm{kg} / \mathrm{m}^{2}\right)$ & $-5,844.98$ & $-5,845.61$ & 1.26 & 0.13 & $-5,846.09$ & 2.20 & 0.14 & $-5,845.59$ & 1.21 & 0.27 \\
\hline $\begin{array}{l}\text { Total fat mass } \\
(\mathrm{kg})\end{array}$ & $-1,870.45$ & $-1,871.69$ & 2.48 & 0.06 & $-1,870.93$ & 0.96 & 0.33 & $-1,872.05$ & 3.21 & 0.07 \\
\hline FMI $\left(\mathrm{kg} / \mathrm{m}^{2}\right)$ & $-6,300.35$ & $-6,301.56$ & 2.42 & 0.06 & $-6,301.32$ & 1.94 & 0.16 & $-6,300.51$ & 0.32 & 0.57 \\
\hline $\begin{array}{l}\text { Total fat mass } \\
(\%)\end{array}$ & $-6,981.80$ & $-6,983.97$ & 4.35 & 0.02 & $-6,983.01$ & 2.43 & 0.12 & $-6,982.02$ & 0.45 & 0.50 \\
\hline Lean mass $(\mathrm{kg})$ & 272.44 & 270.96 & 2.96 & 0.04 & 271.08 & 2.73 & 0.10 & 270.49 & 3.90 & 0.05 \\
\hline LMI $\left(\mathrm{kg} / \mathrm{m}^{2}\right)$ & $-3,834.56$ & $-3,837.19$ & 5.27 & 0.01 & $-3,835.60$ & 2.09 & 0.15 & $-3,834.92$ & 0.73 & 0.39 \\
\hline $\begin{array}{l}\text { Android fat mass } \\
(\mathrm{kg})\end{array}$ & $-5,282.68$ & $-5,284.87$ & 4.39 & 0.02 & $-5,283.27$ & 1.19 & 0.28 & $-5,283.33$ & 1.31 & 0.25 \\
\hline $\begin{array}{l}\text { Gynoid fat mass } \\
(\mathrm{kg})\end{array}$ & $-5,045.57$ & $-5,046.23$ & 1.32 & 0.13 & $-5,046.25$ & 1.36 & 0.24 & $-5,047.20$ & 3.27 & 0.07 \\
\hline $\begin{array}{l}\text { Android:gynoid } \\
\text { fat ratio }\end{array}$ & $-3,004.31$ & $-3,011.57$ & 14.52 & 0.00 & $-3,004.83$ & 1.04 & 0.31 & $-3,008.23$ & 7.83 & 0.01 \\
\hline $\begin{array}{l}\text { Waist circumference } \\
(\mathrm{cm})\end{array}$ & $-2,639.99$ & $-2,641.26$ & 2.55 & 0.06 & $-2,642.76$ & 5.54 & 0.02 & $-2,640.05$ & 0.12 & 0.73 \\
\hline $\begin{array}{l}\text { Hip circumference } \\
(\mathrm{cm})\end{array}$ & $-1,516.06$ & $-1,517.09$ & 2.06 & 0.08 & $-1,520.75$ & 9.38 & 0.00 & $-1,516.63$ & 1.13 & 0.29 \\
\hline $\begin{array}{l}\text { Thigh circumference } \\
(\mathrm{cm})\end{array}$ & $-2,004.34$ & $-2,004.42$ & 0.14 & 0.35 & $-2,008.81$ & 8.04 & 0.00 & $-2,004.79$ & 0.89 & 0.34 \\
\hline WHR & $-3,405.85$ & $-3,407.68$ & 3.65 & 0.03 & $-3,408.96$ & 6.207 & 0.01 & $-3,407.40$ & 3.09 & 0.08 \\
\hline WTR & $-4,561.15$ & $-4,561.96$ & 1.631 & 0.10 & $-4,561.44$ & 0.59 & 0.44 & $-4,561.18$ & 0.07 & 0.79 \\
\hline
\end{tabular}

Estimates were adjusted for age and inbreeding

${ }^{a} p$ values based on a 1/2:1/2 mixture of a $\chi^{2}(1 d f)$ and a point mass of zero

Heart Study [7] women appeared to have higher heritability of BMI and lean mass by DXA, but differences were also not significant considering large SEs.

Few of these studies used the same method of variance decomposition procedures to partition variation in body composition into genetic and environmental effects common to both sexes and to men and women separately and/or calculated genetic correlations between sexes. Several twin studies used self-reported data on height and body weight, potentially influencing outcomes. One study using the same approach as we did found evidence for sex-specific genetic effects for several anthropometric variables, including skinfold thicknesses, in a pedigree of 409 Mexican-Americans but no data were available on fat and lean mass [20]. Consistent with our findings, no significant sex-specific effect was found for weight and height. Aside from these studies, the issue of sex-specific genetic effects on body composition variables has not been formally addressed and especially data from lean and fat mass assessed by DXA are lacking.

The heritability estimates of the body composition variables in our study are well within the range of estimates reported in other family studies but are in general lower than those reported in twin studies. Possible explanations for higher estimates of heritability in twin than in family studies are increased variation in the apparent environmental influences in family studies due to generational differences between parents and their offspring as well as age differences between family members. Heritability in twin studies can, on the other hand, be inflated if the monozygotic twin pairs have been exposed to a more similar environment than the dizygotic twin pairs [6].

Our findings of sex-specific genetic effects on body composition are important for several reasons. Both increased adiposity and android fat deposition are associated with increased risk of chronic disorders such as cardiovascular disease and diabetes. An understanding of the genetic architecture of these risk factors and of their sexual dimorphism should lead to better insight into the relationship between these factors and complex diseases that may differ between sexes. This improved understanding may ultimately lead to better risk prediction and risk reduction. Also, in the search for genes that are associated with obesity, android fat deposition and muscularity, it is important to take into account sex differences by performing sex-stratified analyses. 
There are some limitations to our study. As in many studies on heritability, we have not adjusted our analyses for covariates like smoking, diabetes status, dietary intake and physical activity. The last two variables are not available in our study. In the Diabetes Heart Study, adjustments for these covariates resulted in only minor changes in the heritability estimates of body composition [7]. We studied individuals with a wide age range, including both pre- and postmenopausal women and we tried to overcome this limitation by adjusting all our analyses for age. Insufficient power precluded us from studying sex-specific differences in different age groups. It is possible that the sex-specific effects we found may vary by age since sex differences in body composition are also not constant across the age range and most pronounced in adolescence and young adulthood [10]. Previous studies have examined possible age effects on genetic and environmental influences on BMI with unclear and inconsistent results $[3,6,16]$. The genetic make-up of genetically isolated populations may differ from a general population as a result of genetic drift and founder effects. Even though our population is a genetic isolate we found no evidence that it deviates much from the general population in its genetic composition [23, 34]. However, as was pointed out again recently [35], heritability estimates are by definition population-specific and replication of our findings in other populations is necessary. We acknowledge that multiple testing may influence some of the significant findings in our study. Corrections (e.g. Bonferroni) would be too stringent since most body composition traits we studied are highly correlated. Considering the consistency of the results across sexes, we do not expect multiple testing to play a substantial role in the interpretation of our findings.

The strength of the study is the availability of a large population with extensive information on body composition and genealogy and the use of validated formal testing of sex-specific effects with variance decomposition procedures.

In conclusion, we found evidence for sex-specific genetic effects that may underlie sex differences in several body composition traits. The findings are relevant for the design of genetic association studies like genome wide association and for studies on the relationship of body composition and fat distribution with common diseases such as cardiovascular disease and type 2 diabetes.

Acknowledgements This work was supported by a joint grant from the Center of Medical Systems Biology (CMSB). We thank the participants and relatives from the ERF study, the local healthcare centres and the municipalities for making this study possible.

Duality of interest The authors declare that there is no duality of interest associated with this manuscript.
Open Access This article is distributed under the terms of the Creative Commons Attribution Noncommercial License which permits any noncommercial use, distribution, and reproduction in any medium, provided the original author(s) and source are credited.

\section{References}

1. Comuzzie AG, Allison DB (1998) The search for human obesity genes. Science 280:1374-1377

2. Harris JR, Tambs K, Magnus P (1995) Sex-specific effects for body mass index in the new Norwegian twin panel. Genet Epidemiol $12: 251-265$

3. Herskind AM, McGue M, Sorensen TI, Harvald B (1996) Sex and age specific assessment of genetic and environmental influences on body mass index in twins. Int $\mathrm{J}$ Obes Relat Metab Disord 20:106-113

4. Carey DG, Nguyen TV, Campbell LV, Chisholm DJ, Kelly P (1996) Genetic influences on central abdominal fat: a twin study. Int J Obes Relat Metab Disord 20:722-726

5. Samaras K, Spector TD, Nguyen TV, Baan K, Campbell LV, Kelly PJ (1997) Independent genetic factors determine the amount and distribution of fat in women after the menopause. J Clin Endocrinol Metab 82:781-785

6. Schousboe K, Visscher PM, Erbas B et al (2004) Twin study of genetic and environmental influences on adult body size, shape, and composition. Int J Obes Relat Metab Disord 28:39-48

7. Hsu FC, Lenchik L, Nicklas BJ et al (2005) Heritability of body composition measured by DXA in the diabetes heart study. Obes Res 13:312-319

8. Malis C, Rasmussen EL, Poulsen P et al (2005) Total and regional fat distribution is strongly influenced by genetic factors in young and elderly twins. Obes Res 13:2139-2145

9. Blair ML (2007) Sex-based differences in physiology: what should we teach in the medical curriculum? Adv Physiol Educ 31:23-25

10. Wells JC (2007) Sexual dimorphism of body composition. Best Pract Res Clin Endocrinol Metab 21:415-430

11. Eaves LJ, Last KA, Young PA, Martin NG (1978) Model-fitting approaches to the analysis of human behaviour. Heredity 41:249-320

12. Neale MC, Cardon LR (1992) Methodology for genetic studies of twins and families. Kluwer Academic Publishers, Dordrecht, the Netherlands

13. Allison DB, Heshka S, Neale MC, Lykken DT, Heymsfield SB (1994) A genetic analysis of relative weight among 4,020 twin pairs, with an emphasis on sex effects. Health Psychol 13:362-365

14. Hur YM (2007) Sex difference in heritability of BMI in South Korean adolescent twins. Obesity 15:2908-2911

15. Stunkard AJ, Harris JR, Pedersen NL, McClearn GE (1990) The body-mass index of twins who have been reared apart. N Engl J Med 322:1483-1487

16. Korkeila M, Kaprio J, Rissanen A, Koskenvuo M (1991) Effects of gender and age on the heritability of body mass index. Int $\mathrm{J}$ Obes 15:647-654

17. Souren NY, Paulussen AD, Loos RJ et al (2007) Anthropometry, carbohydrate and lipid metabolism in the East Flanders Prospective Twin Survey: heritabilities. Diabetologia 50:2107-2116

18. Tambs K, Moum T, Eaves LJ et al (1991) Genetic and environmental contributions to the variance of body mass index in a sample of first- and second-degree relatives. Am J Hum Biol $3: 257-261$

19. Weiss LA, Pan L, Abney M, Ober C (2006) The sex-specific genetic architecture of quantitative traits in humans. Nat Genet $38: 218-222$ 
20. Comuzzie A, Blangero J, Mahaney M, Mitchell B, Stern M, Maccluer J (1993) Quantitative genetics of sexual dimorphism in body fat measurements. Am J Hum Biol 5:725-734

21. Vaessen N, Heutink P, Houwing-Duistermaat JJ et al (2002) A genome-wide search for linkage-disequilibrium with type 1 diabetes in a recent genetically isolated population from the Netherlands. Diabetes 51:856-859

22. Sayed-Tabatabaei FA, van Rijn MJ, Schut AF et al (2005) Heritability of the function and structure of the arterial wall: findings of the Erasmus Rucphen Family (ERF) study. Stroke 36:2351-2356

23. Santos RL, Zillikens MC, Rivadeneira FR et al (2006) Heritability of fasting glucose levels in a young genetically isolated population. Diabetologia 49:667-672

24. Wigginton JE, Abecasis GR (2005) PEDSTATS: descriptive statistics, graphics and quality assessment for gene mapping data. Bioinformatics 21:3445-3447

25. Boichard D (2002) PEDIG: a FORTRAN package for pedigree analysis studied for large populations. 7th World Congress of Genet Appl Livest Prod, Montpellier, France, paper 28-13 (http://www-sgqa. jouy.inra.fr/IMG/pdf/User_s_Guide.pdf)

26. Almasy L, Blangero J (1998) Multipoint quantitative-trait linkage analysis in general pedigrees. Am J Hum Genet 62:1198-1211

27. Hopper JL, Mathews JD (1982) Extensions to multivariate normal models for pedigree analysis. Am J Hum Genet 46:373-383
28. Lange K, Boehnke M (1983) Extensions to pedigree analysis. IV. Covariance components models for multivariate traits. Am J Med Genet 14:513-524

29. Falconer DS (1981) Introduction to quantitative genetics, second edition. Longmans Green, London/New York

30. Martin LJ, Mahaney MC, Almasy L et al (2002) Leptin's sexual dimorphism results from genotype by sex interactions mediated by testosterone. Obes Res 10:14-21

31. Brown LB, Streeten EA, Shuldiner AR, Almasy LA, Peyser PA, Mitchell BD (2004) Assessment of sex-specific genetic and environmental effects on bone mineral density. Genet Epidemiol 27:153-161

32. Martin LJ, Cole SA, Hixson JE et al (2002) Genotype by smoking interaction for leptin levels in the San Antonio Family Heart Study. Genet Epidemiol 22:105-115

33. Self SG, Liang KY (1987) Asymptomatic properties of maximum likelihood ratio test under nonstandard conditions. J Am Stat Assoc 82:605-610

34. Pardo LM, MacKay I, Oostra B, van Duijn CM, Aulchenko YS (2005) The effect of genetic drift in a young genetically isolated population. Ann Hum Genet 69:288-295

35. Visscher PM, Hill WG, Wray NR (2008) Heritability in the genomics era-concepts and misconceptions. Nat Rev Genet 9:255-266 